OPEN ACCESS

Edited by:

Gayane Manukyan,

National Academy of Sciences of the

Republic of Armenia, Armenia

Reviewed by:

Rudra Bhowmick,

Oklahoma State University, USA

María-Julieta González,

Universidad de Chile, Chile

Gabriel J. Tobón,

Fundación Valle del Lili, Colombia

*Correspondence:

Yves Renaudineau,

Laboratory of Immunology and Immunotherapy, Brest University

Medical School Hospital,

CHU Morvan, 2 Avenue Foch,

BP824, Brest F29609, France

yves.renaudineau@univ-brest.fr

Specialty section:

This article was submitted to Microbial Immunology, a section of the journal Frontiers in Immunology

Received: 12 June 2015 Accepted: 11 August 2015 Published: 26 August 2015

Citation:

Konsta OD, Le Dantec C, Charras A, Brooks WH, Arleevskaya MI, Bordron A and Renaudineau Y (2015)

An in silico approach reveals associations between genetic and epigenetic factors within regulatory elements in B cells from primary

Sjögren's syndrome patients.

Front. Immunol. 6:437.

doi: 10.3389/fimmu.2015.00437

\section{An in silico approach reveals associations between genetic and epigenetic factors within regulatory elements in B cells from primary Sjögren's syndrome patients}

\author{
Orsia D. Konsta ${ }^{1}$, Christelle Le Dantec ${ }^{1}$, Amandine Charras ${ }^{1}$, Wesley H. Brooks ${ }^{2}$, \\ Marina I. Arleevskaya ${ }^{3}$, Anne Bordron ${ }^{1}$ and Yves Renaudineau ${ }^{1,4 *}$
}

${ }^{1}$ INSERM ESPRI, ERI29/EA2216, SFR ScInBioS, LabEx IGO "Immunotherapy Graft Oncology", Innovative Medicines Initiative PRECISESADS, Réseau épigénétique et réseau canaux ioniques du Cancéropole Grand Ouest, European University of Brittany, Brest, France, ${ }^{2}$ Department of Chemistry, University of South Florida, Tampa, FL, USA, ${ }^{3}$ Department of Rheumatology, Kazan State Medical Academy, Kazan, Russia, ${ }^{4}$ Laboratory of Immunology and Immunotherapy, CHU Morvan, Brest, France

Recent advances in genetics have highlighted several regions and candidate genes associated with primary Sjögren's syndrome (SS), a systemic autoimmune epithelitis that combines exocrine gland dysfunctions, and focal lymphocytic infiltrations. In addition to genetic factors, it is now clear that epigenetic deregulations are present during SS and restricted to specific cell type subsets, such as lymphocytes and salivary gland epithelial cells. In this study, 72 single nucleotide polymorphisms (SNPs) associated with 43 SS gene risk factors were selected from publicly available and peer reviewed literature for further in silico analysis. SS risk variant location was tested revealing a broad distribution in coding sequences (5.6\%), intronic sequences (55.6\%), upstream/downstream genic regions (30.5\%), and intergenic regions (8.3\%). Moreover, a significant enrichment of regulatory motifs (promoter, enhancer, insulator, DNAse peak, and expression quantitative trait loci) characterizes SS risk variants (94.4\%). Next, screening SNPs in high linkage disequilibrium ( $r^{2} \geq 0.8$ in Caucasians) revealed 645 new variants including 5 SNPs with missense mutations, and indicated an enrichment of transcriptionally active motifs according to the cell type (B cells $>$ monocytes $>T$ cells $\gg$ A549). Finally, we looked at SS risk variants for histone markers in B cells (GM12878), monocytes (CD14 ${ }^{+}$) and epithelial cells (A548). Active histone markers were associated with SS risk variants at both promoters and enhancers in B cells, and within enhancers in monocytes. In conclusion and based on the obtained in silico results that need further confirmation, associations were observed between SS genetic risk factors and epigenetic factors and these associations predominate in B cells, such as those observed at the FAM167A-BLK locus.

Keywords: Sjögren's syndrome, genetics, epigenetics, polymorphism, in silico, histone modifications, B cells 


\section{Introduction}

Primary Sjögren's syndrome (SS) is a systemic autoimmune epithelitis affecting exocrine glands, such as salivary and lacrimal glands (1). The clinical manifestations of SS include dry mouth (xerostomia), dry eyes (keratoconjunctivitis sicca), systemic features, and patients have a 20- to 40 -fold increased risk of developing lymphoma (2-4). Histological examination shows focal and peri-epithelial $\mathrm{T}$ and $\mathrm{B}$ cell infiltration plus macrophages in exocrine glands and parenchymal organs, such as kidney, lung, and liver (5). SS is characterized by the presence of circulating autoantibodies (Ab) against the sicca syndrome (SS)A/Ro and SSB/La ribonucleoprotein particles (6).

It is estimated that there are over 120 million single nucleotide polymorphisms (SNPs) in the human genome (NCBI dbSNP database, Build 143) and, among them, hundreds are disease risk variants for autoimmune diseases (AID) with the particularity that they are for the vast majority excluded from proteincoding regions (exon) and present within regulatory areas (7, 8). Regulatory SNPs control genes through an effect on (i) the transcriptional machinery when present within a gene regulatory region [promoter, enhancer, insulator (a gene regulatory element that blocks interaction between enhancers and promoters), and expression quantitative trait loci (eQTL)], (ii) the spliceosomal complex formation that controls intron excision, (iii) the activation of mRNA non-sense-mediated decay (NMD), and (iv) the control of messenger RNA stability through microRNA ( $3^{\prime}$-UTR). In SS, the list of genetic variations is growing with the particularity that the odds ratio $(\mathrm{OR})$ is usually modest $(\mathrm{OR}<1.5)$ with the exception of the HLA genes that have a significant OR (usually $>2$ ) (9). The associated risk genes analysis supports immunopathological pathways in SS, such as antigen presentation, cytokine signaling, and the NF- $\mathrm{KB}$ pathway (10). The characterization of regulatory SNPs in SS remains to be established.

In SS, several arguments support a role for epigenetic deregulation in disease initiation and progression $(11,12)$. The first clue was that two drugs, procainamide and hydralazine, induced SS in humans by blocking DNA methylation (13). Moreover, defects in DNA methylation characterize T cells, B cells, and salivary gland epithelial cells from SS patients (14-16), and such defects were associated with the expression of genes usually repressed by DNA methylation, such as transposons and miRNAs in salivary glands from SS patients $(17,18)$. Last, but not least, histone epigenetic markers and ribonucleoprotein post-translational modifications are immunogenic leading to autoAb production (14).

Accordingly, the aim of this work was to test the association between genetic and epigenetic determinants in SS. In the following, we pursue a two-staged analysis. First, we characterized a large panel of SS risk variants to reveal that they are predominantly present within regulatory elements. Second, we further explored the striking associations of those regulatory elements with cellular specificity and particularly in immune cells.

\section{Materials and Methods}

\section{SS Genetic Risk Factors}

Data mining based on peer reviewed literature information (PubMed) and publicly available databases (centralgwas.org) served in the compilation of a list of 43 gene risk factors and their reported variants $(n=72)$ in SS (Table S1 in Supplementary Material) (19-49). The number of SS patients and controls were also reported as well as the OR average (95\%), when available. The gene list used in this study was manually updated further to include gene function, SNP number (dbSNP database), and genomic location according to the human genome reference GRCh38. Genetic variants and their observed associations with clinical and functional phenotype were submitted to The National Center for Biotechnology Information (NCBI) ClinVar database ${ }^{1}$. The gene list was tested with the FatiGO web interface AmiGO2 ${ }^{2}$ for functional enrichment.

\section{Functional/Regulatory Genome Annotation Data}

The variant effect predictor (VEP) tool ${ }^{3}$ was used to determine the location of the variants (exon, intron, $5^{\prime} / 3^{\prime}$-UTR, Up/Downstream genic sequence, and intergenic section) and their consequences [missense, non-coding transcript, splice donor variant, and target of non-sense-mediated mRNA decay (NMD)].

Assessment of the SNPs functional relevance was further completed by requesting Regulome DB V1.1 ${ }^{4}$, and HaploRegV2 $2^{5}$, data bases $(50,51)$ for promoter [RNA polymerase II (Pol II) binding], enhancer (H3K27Ac, H3K36me3, and/or H3K27me3 binding in the absence of Pol II binding), insulator [CCCCTCbinding factor (CTCF)], transcription factor (TF) binding, DNase peak, and eQTL.

\section{Linkage Disequilibrium}

Following SNP selection, the HaploRegV2 web portal was used to identify SNPs in linkage disequilibrium (LD, $\left.R^{2} \geq 0.80\right)$ in Europeans from the 1000 genome project using a maximum distance between variants of $200 \mathrm{~kb}$ in order to cover the enhancer elements (51).

\section{Statistical Analysis}

Pearson's Chi-squared test with Yate's continuity correction, when appropriate, was used to evaluate the significance of differences between the regulatory motifs and the histone chromatin immunoprecipitation (ChIP) experiments. A probability $(P)$ of $<0.05$ was considered significant.

\section{Results}

\section{Autoimmune-Related Genes Associated with SS}

A list of 43 SS-associated gene risk factors corresponding to 72 SNPs, referred to as SS risk variants, was extracted from the scientific literature (Figure 1). Among the risk factors, half (36/72) were associated with another AID (systemic lupus erythematosus, rheumatoid arthritis, systemic sclerosis, inflammatory bowel disease, autoimmune thyroiditis disease, insulin-dependent diabetes, primary biliary cirrhosis, autoimmune hepatitis), allergy, infections, and cancer, including B/T cell lymphomas. This partial

\footnotetext{
${ }^{1}$ http://www.ncbi.nlm.nih.gov/clinvar

${ }^{2}$ http://amigo2.geneontology.org

${ }^{3}$ http://www.ensembl.org

${ }^{4} \mathrm{http}: / /$ regulome.stanford.edu

${ }^{5}$ http://www.broadinstitute.org
} 


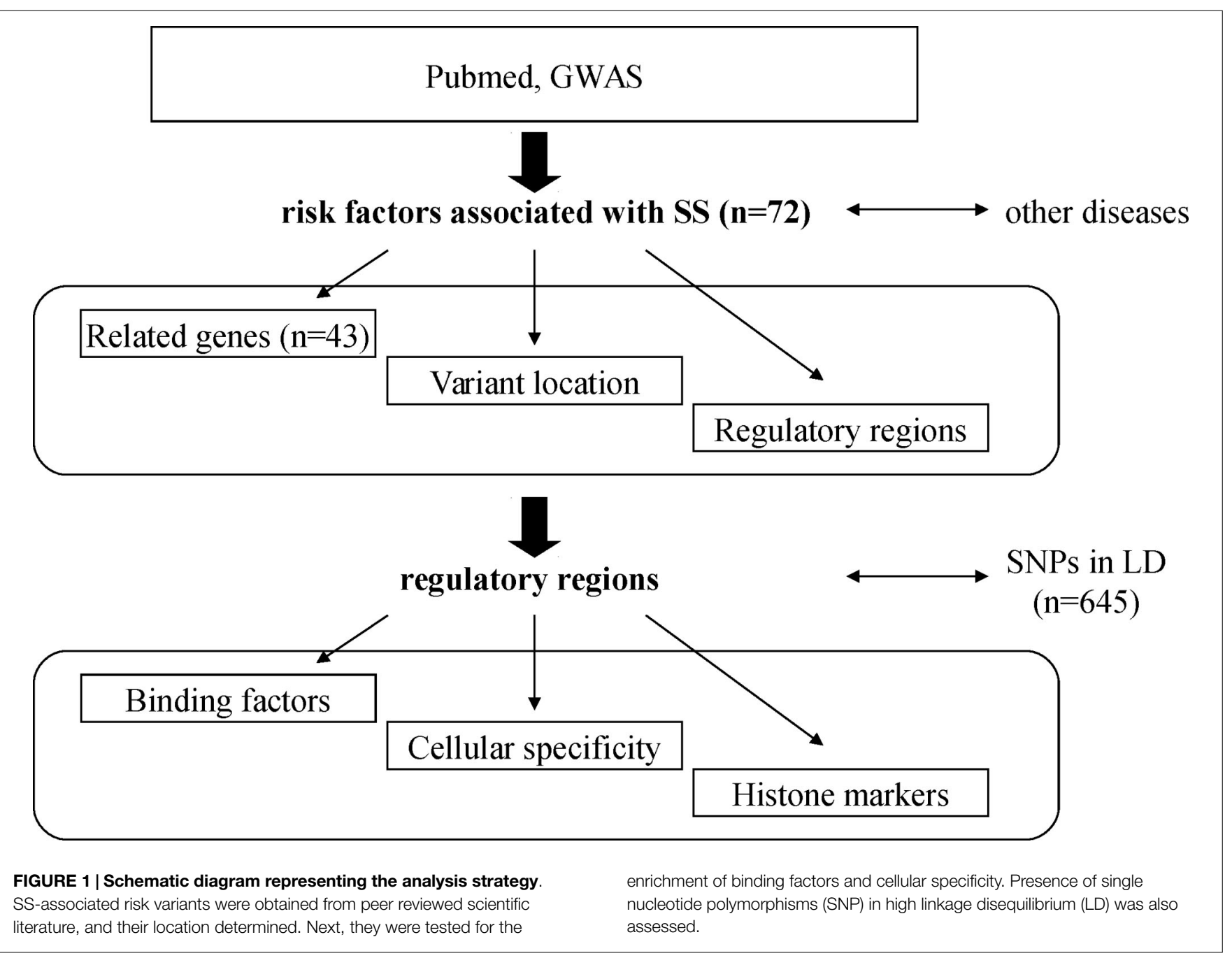

overlap suggests that both common and distinct genetic traits are present in SS and equally distributed.

\section{Variant Location}

Next, we used the VEP predictor tool in order to test the location of the different variants (Figure 2). Applied to the 72 SS risk variants, the VEP tools identified 4/72 (5.6\%) exonic variants with missense mutations (IL17F, rs763780; MBL2, rs1800450; PTPN22, rs2476601; and TNFA1P3, rs2230926), and 40/72 (55.6\%) intronic variants including an alternative splice donor variant (IRF5, rs2004640) and 4 variants that were predicted as targets of non-sense-mediated mRNA decay (NMD: ICA1, rs17143355; SLC25A40, rs10276819; STAT1, rs13005843; and TNIP1, rs6579837). Moreover, two $5^{\prime}$-UTR variants (CD14, rs2569190; and NCR3, rs11575837), one $3^{\prime}$-UTR variant (IL10, rs3024498), 12/72 (16.7\%) upstream genic variants, 7/72 (9.7\%) downstream genic variants, and 6/72 (8.3\%) intergenic variants $(>10 \mathrm{~kb})$ were also observed.

\section{Regulatory Regions and DNA Binding Molecules}

We then used a combination of three tools based on information from the ENCODE program (VEP) and from both the ENCODE and the Roadmap Epigenome programs (RegulomDB and HaploReg v2) to determine whether SS risk variants are likely to be within promoters, enhancers, or insulators. These regulatory motifs were defined according to the available ChIP results from multi-cell analysis showing $21 / 72(29.2 \%)$ promoters, $41 / 72$ (56.9\%) enhancers, and 5/72 (6.9\%) insulators. Of particular note, within the four SNPs with missense mutations, one promoter and two insulators were detected (Figure 3). Moreover, 34/72 (47.2\%) DNase hypersensitive regions (DNase peak) and 12/72 (16.7\%) eQTL were recovered. Looking specifically at promoters and enhancers, data from ChIP experiments revealed that NF$\kappa \mathrm{B}(n=5)$, STATs $(n=3)$, and EGR-1 $(n=3)$ were predominant in promoters, and NF- $\kappa \mathrm{B}(n=3)$ in enhancers. For the remaining 5/72 (6.9\%) SNPs, no regulatory functions were assigned which is significantly lower than the expected rate of $56.2 \%$ $\left(P<10^{-6}\right)(50)$.

\section{Genes in High Linkage Disequilibrium}

In order to improve the analysis, we used the HaploReg v2 tool to include 645 new SNPs that were identified to be in high LD with the 72 annotated SNPs (Table 1). This tool identifies 34 new genes, including one microRNA (Mir4752), five SNPs with 


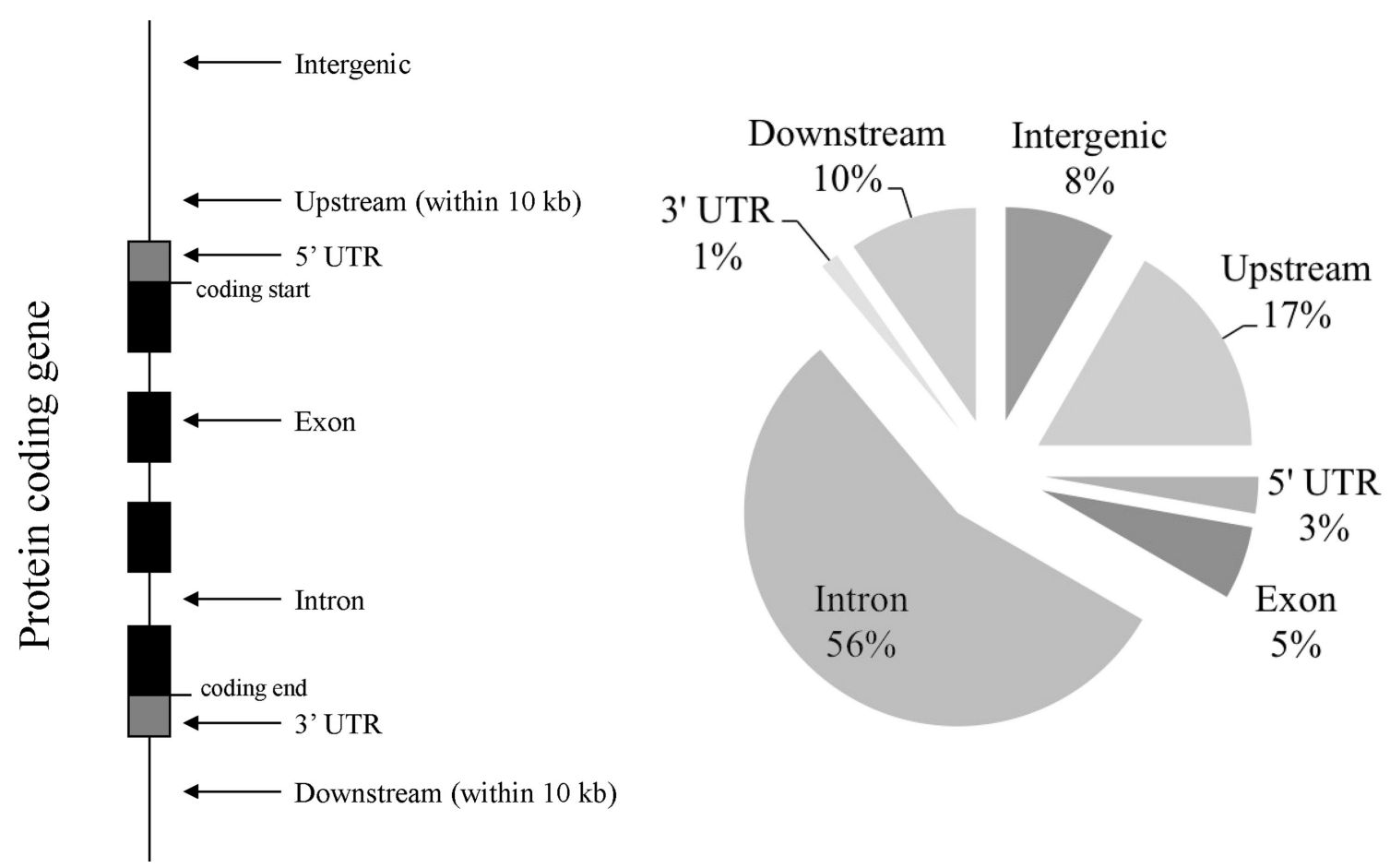

FIGURE 2 | Occurrences of SS risk variants according to the protein-coding gene location.

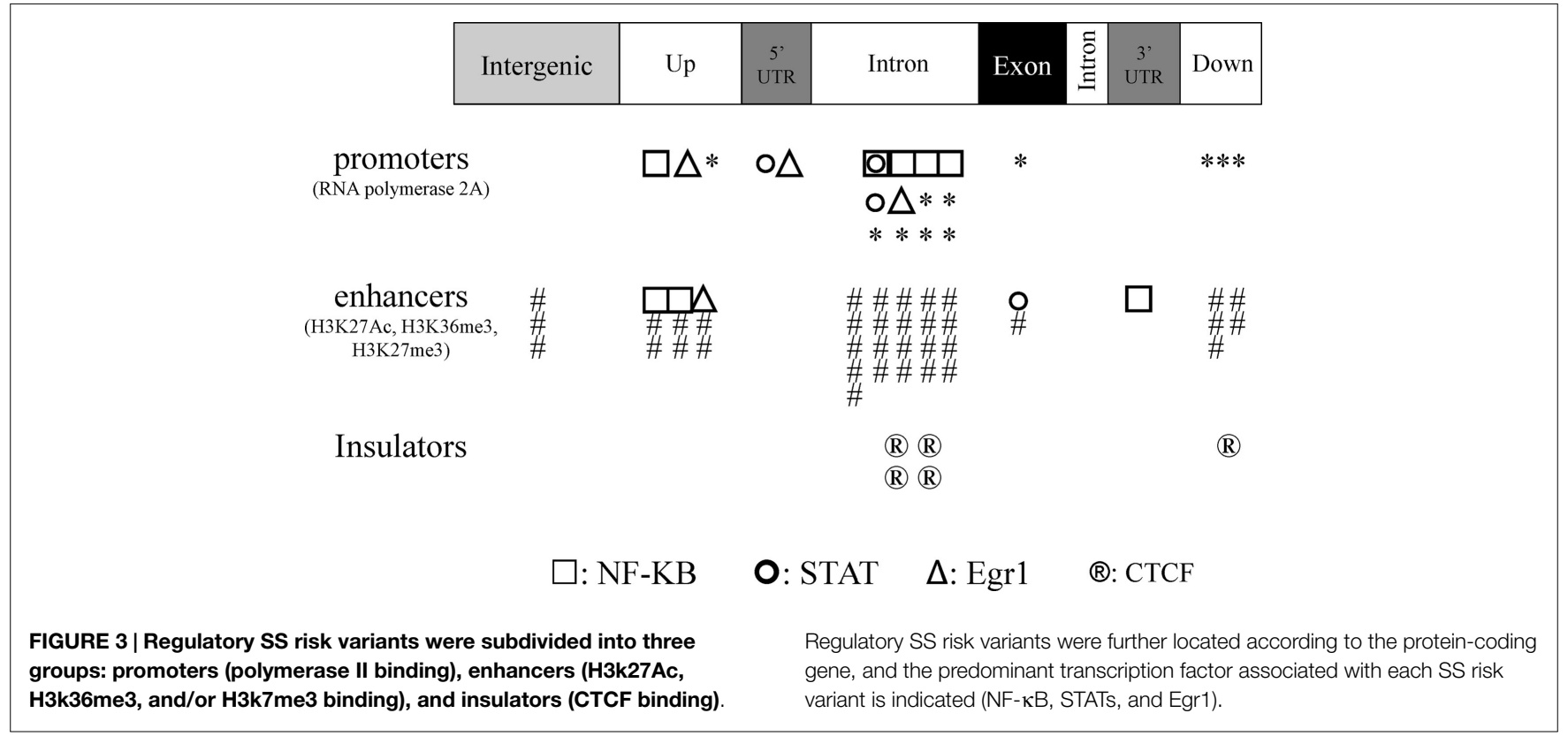

missense mutations (rs1041981 in LTA; rs78957773 in MCCD1, rs2230539 in PKN1, and rs52817781 plus rs2233290 in TNIP1), and indicated an overall 15.8 -fold enrichment of enhancers in human embryonic cells $(\mathrm{H} 1 ; P=0.0001)$ and 4.9 -fold enrichment of enhancers in the GM12878 EBV-transformed lymphoblastoid B cell line $(P=0.0014)$. A significant enrichment of transcriptionally active sites, identified by DNAse enrichment analysis, was observed in the SNP set with a 21-fold increase in GM12878 lymphoblastoid B cells $\left(P<10^{-6}\right), 10.8$-fold increase in CD $14^{+}$ monocytes $(P=0.00002), 9.2$-fold increase in $\mathrm{CD} 20^{+} \mathrm{B}$ cells $(P=0.001), 8.2$ - to 8.5 -fold increase in T cells $(P<0.005)$, and 5.7 -fold increase in the A549 epithelial cell line $(P=0.005)$. Moreover, gene ontology biological process analysis (AmiGO2) identified "regulation of immune response" $\left(P=2.16 \times 10^{-18}\right.$ and $\left.9.2 \times 10^{-17}\right)$, "positive regulation of cytokine production" $\left(P=1.56 \times 10^{-11}\right.$ and $\left.1.22 \times 10^{-13}\right)$, "response to molecule of 
TABLE 1 | Gene risk factors associated with primary Sjögren's syndrome (SS).

SS gene risk factors extracted from the literature

BAK1, BCL2, BLK, C4A, CCL2, CD14, CD40, CD4OLG, CHRM3, CXCR5, EBF1, FAM167A, GTF21, HLA DPB1, HLA-DQA1, HLA-DQB1, HLA-DRA, ICA1, IKBKE, IL10, IL12A, IL17F, IL21, IRF5, LILRA3, LTA*, MBL2, NCR3, NFKB1, OR2B11, PKN1 $^{\star}$, PTPN22, SLC25A40, STAT1, STAT4, TNF, TNFA1P3, TNFSF13B, TNIP1 ${ }^{\star}$, TNPO3, TNFSF4, Trim21

New genes in high linkage disequilibrium

ABCB1, AC053545.3, ADAD1, AF213884.2, APBB3, ATP6V1G2, ATP6V1G2-DDX39B, BTNL2, C6orf10, CCL11, CCL7, CTD-2049J23.2, DBF4, GGNBP1, HCG23, HLA-DPA1, IL2, KIAA1109, MCCD1*, Metazoa_SRP, MIR4752, NDUFA2, NFKBIL1, PTGER1, RP11-10J5.1, RP11-356I2.2, RP11-356l2.4, RP3-527F8.2, RP5-998H6.2, RSBN1, RUNDC3B, SLC25A40, snoU13, XXbac-BPG254F23.7

Bold missense mutations.

*Missense mutations detected by linkage disequilibrium.

bacterial origin" $\left(P=4.9 \times 10^{-7}\right.$ and $\left.6.2 \times 10^{-9}\right)$, and "cellular response to interferon" $\left(P=1.82 \times 10^{-7}\right.$ and $\left.1.86 \times 10^{-7}\right)$ as the most significant functions associated with the SS gene risk factors tested alone or associated with the genes revealed by the LD analysis, respectively.

\section{Cell Type-Specific Analysis Revealed Activated Enhancer and Promoter Histone Markers at SS Risk Variants in B Cells}

To further explore cell type specific activation in promoters and enhancers at SS risk variants and according to the critical role played in the disease by epithelial cells, lymphocytes, and macrophages, we selected from the 18 ENCODE available cells: the human lung adenocarcinoma cell line A549 for epithelial cells, the GM12878 lymphoblastoid cells for B cells, and the peripheral blood $\mathrm{CD}_{14}{ }^{+}$monocytes for macrophages. For these three cell types, we mapped SS risk variants to markers of active promoters (H3K4me2, $\mathrm{H} 3 \mathrm{~K} 4 \mathrm{me} 3$, and $\mathrm{H} 3 \mathrm{~K} 9 \mathrm{Ac})$, and to markers of active enhancers (H3K36me3 and H3K4me1) (52). In addition, $\mathrm{H} 3 \mathrm{~K} 27 \mathrm{Ac}$ was selected as a marker of activity, and $\mathrm{H} 3 \mathrm{~K} 27 \mathrm{me} 3$ as an inactive marker of enhancers.

As shown in Figure 4A and with regards to the 21 promoter SS risk variants, the three active promoter markers (H3K4me2, $\mathrm{H} 3 \mathrm{~K} 4 \mathrm{me} 3$, and $\mathrm{H} 3 \mathrm{~K} 9 \mathrm{Ac})$ were significantly enriched in B cells (GM12878) in contrast to the epithelial cells (A549) and monocytes $(0.01<P<0.0006$, Chi square with Yate's correction). The active marker $\mathrm{H} 3 \mathrm{~K} 27 \mathrm{Ac}$ was enriched in $\mathrm{B}$ cells and monocytes in contrast to epithelial cells ( $P=0.0001$ and $P=0.02$, respectively).

The same analysis was performed with the 41 enhancer SS risk variants (Figure 4B) revealing an enrichment of the enhancer active marker $\mathrm{H} 3 \mathrm{~K} 36 \mathrm{me} 3$ in both $\mathrm{B}$ cells and monocytes in contrast to A459 cells ( $P=0.02$ and $P=0.005$, respectively). The active marker H3K27Ac was enriched in B cells $(P=0.0001)$, and, although not significant, there is a trend for a monocyte enrichment in contrast to epithelial cells. In summary, these findings highlight the critical role of epigenetic factors in B cells to control both promoter and enhancer SS risk variants, and in monocytes to control enhancer SS risk variants.

\section{FAM167A-BLK Locus}

In order to validate our observations, and based on three reports, including the genome wide association study (GWAS) performed by Lessard et al., in 395 patients with SS and 1975 controls from European origins $(31,35,41)$, the FAM167A-BLK locus (Chr 8:11421463-11564604) was selected to position the 8 FAM167A-BLK SS risk variants plus two $5^{\prime}$-UTR variants selected from the LD analysis and previously identified as lupus risk variants (53). These two SNPs are in high LD with 4/8 SS risk variants [rs922483 is in high LD with rs2736340 $\left(r^{2}=0.81\right)$, rs13277113 $\left(r^{2}=0.83\right)$, and rs2736345 $\left(r^{2}=0.96\right)$; and $\mathrm{rs} 2250788$ is in high LD with rs2254546 $\left.\left(r^{2}=0.98\right)\right]$. As shown in Figure 4C, the 10 selected SNPs were positioned in the FAM167A-BLK locus revealing three groups. The first group contains an isolated SNP (rs12549796) that was present in an intronic part of the FAM167A gene. A second group $(n=7)$ was present in the vicinity of the BLK promoter and exon 1 , and a third group $(n=2)$ was present $\sim 35 \mathrm{~kb}$ downstream BLK promoter.

Next, as revealed by querying the Ensembl database using $\mathrm{H} 3 \mathrm{~K} 27 \mathrm{Ac}$ to mark active promoters and enhancers, SNPs were positioned within 9/10 H3K27Ac active motifs in B cells (GM12878), which is in contrast to $2 / 10 \mathrm{H} 3 \mathrm{~K} 27 \mathrm{Ac}$ active motifs in monocytes, and none in epithelial cells. Such associations between genetic and epigenetic factors within regulatory elements in B cells for the FAM167A-BLK locus were further reinforced by using the RegulomeDB tool that summarizes results from the ENCODE and Epigenetic Roadmap programs. As indicated Table 2, the RegulomeDB tool supports that SS risk factors at FAM167A-BLK locus would predominantly affect B cells (lymphoblastoid and naive $B$ cells) and, to a lesser extent, monocytes, $T$ cells (naïve, $\mathrm{TH} 2$, and Treg), mesenchymal stem cells, and fibroblasts.

\section{Discussion}

Primary SS is an autoimmune disease with a genetic basis in which at least 40 gene risk factors may be involved, including BLK, IRF5, STAT4, and the HLA locus. However, these genetic risk factors alone cannot explain all of the disease risk factors and, in particular, environmental risk factors (e.g., viruses, hormones ... ) that are likely to play a critical role in the process of the disease. Given the complexity of the disease, epigenetic analyses are conducted to provide new insights into the disease as DNA methylation patterns, chromatin structures, and microRNA are influenced both by the genetic machinery and by environmental factors $(13,54,55)$. The primary role of the epigenome is to regulate, in a cell-specific manner, cellular development, and differentiation and such effects vary between individuals with age as revealed by testing identical twins (56), or between smokers and non-smokers (57). Furthermore, genetic variants and, in particular, non-coding and regulatory SNPs can influence cell type specific regions marked by accessible regions, thus opening new perspectives to better characterize disease risk factors and cell types contributing to the diseases which was the aim of the present in silico analysis.

Applied to SS, such strategy was fruitful in suggesting the existence of associations between genetic and epigenetic alterations in the setting of the disease. Indeed, a cell-specific overlap 

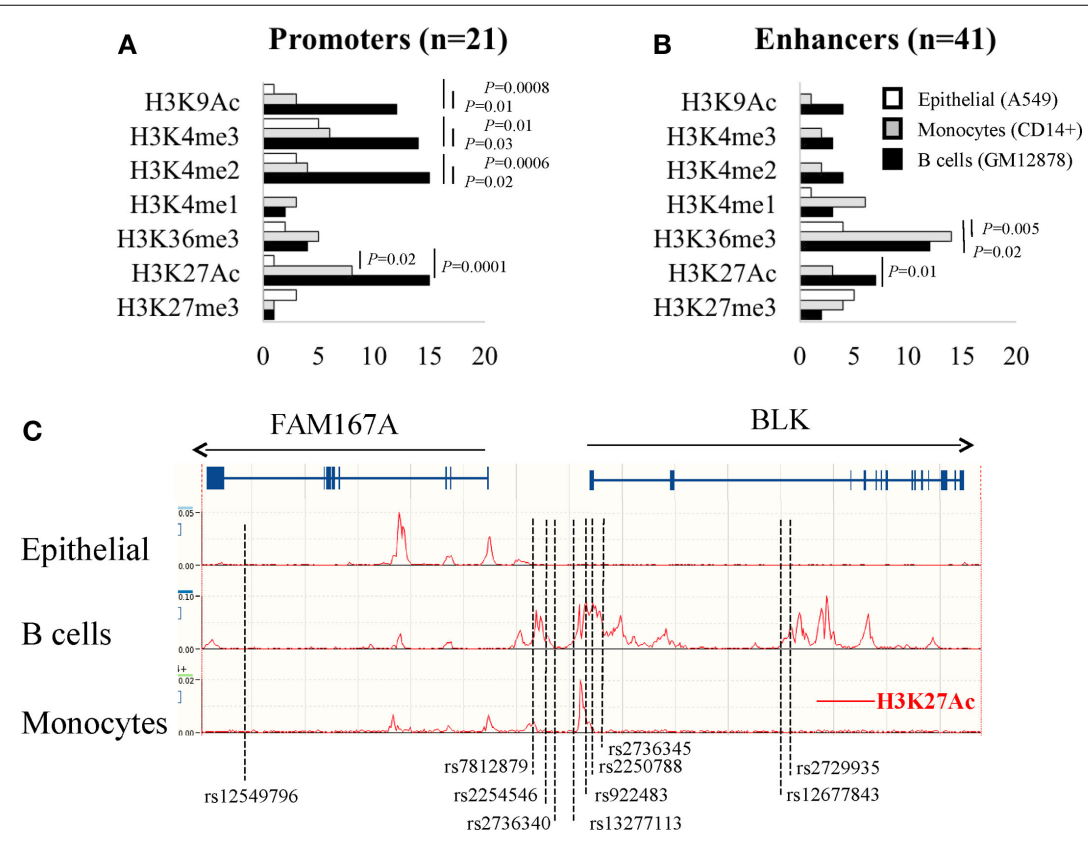

FIGURE 4 | Analysis of histone modifications in the promoters (A) and enhancers (B) of SS risk variants within A549 epithelial cells, B cell lymphobastoid GM12878 cells, and CD14 ${ }^{+}$monocytes. (C) In the lymphoblastoid GM12878 B cell line, SS genetic variants and the active histone markers H3k27Ac are co-localized in and around the FAM167A-BLK locus (http://www.ensembl.org).

TABLE 2 | Summary of the cell type enrichment markers for FAM167-BLK variants according to the RegulomeDB prediction web tool.

\begin{tabular}{|c|c|c|c|c|c|}
\hline SNP & Promoter (histone markers) & Enhancer (histone markers) & Open chromatin (DNase) & eQTL & Pol II (ChIP-Seq) \\
\hline rs12549796 & No & Mesenchymal stem cells & Fibroblast & No & No \\
\hline rs7812879 & No & $\begin{array}{l}\text { B lymphoblastoid, B cells, } \\
\text { monocytes }\end{array}$ & No & B lymphoblastoid & No \\
\hline rs2254546 & No & B cells & No & B lymphoblastoid & No \\
\hline rs2736340 & No & B cells & No & $\begin{array}{l}\text { B lymphoblastoid, } \\
\text { monocytes }\end{array}$ & No \\
\hline rs13277113 & B lymphoblastoid & B cells, monocytes & $\begin{array}{l}\text { B lymphoblastoid, } \\
\text { B cells }\end{array}$ & B lymphoblastoid & No \\
\hline rs922483 & $\begin{array}{l}\text { B lymphoblastoid, B cells, } \\
\text { T cells, monocytes }\end{array}$ & Fibroblast & $\begin{array}{l}\text { B lymphoblastoid, } \\
\text { B cells, TH2, Treg }\end{array}$ & B lymphoblastoid & B lymphoblastoid \\
\hline rs2250788 & $\begin{array}{l}\text { B lymphoblastoid, B cells, } \\
\text { T cells, monocytes }\end{array}$ & Fibroblast & $\begin{array}{l}\text { B lymphoblastoid, } \\
\text { B cells }\end{array}$ & No & B lymphoblastoid \\
\hline rs2736345 & $\begin{array}{l}\text { B lymphoblastoid, B cells, } \\
\text { T cells }\end{array}$ & $\begin{array}{l}\text { Fibroblast, Mesanchymal } \\
\text { stem cells }\end{array}$ & $\begin{array}{l}\text { B lymphoblastoid, } \\
\text { B cells, TH2 }\end{array}$ & B lymphoblastoid & B lymphoblastoid \\
\hline rs12677843 & No & No & No & No & No \\
\hline rs2729935 & No & B lymphoblastoid, B cells & No & No & No \\
\hline
\end{tabular}

exists between identified SS risk variants and the regulatory switches found by the ENCODE program, thus suggesting that DNA-protein binding and gene transcription are affected by the SNPs. Remarkably, almost all SS risk variants tested (94.4\%) had in silico evidence of regulatory functions including the $3 / 4$ missense SNPs and the 37/40 intronic SNPs. In addition and according to our in silico observations that need further confirmation, it could be postulated that SS risk variants control DNA-protein binding leading to the regulation of cell-specific promoters ( $\mathrm{Pol}$ II, NF- KB, STATs), enhancers (NF- $\mathrm{KB}$ ), and insulators (CTCF). These results also suggest that there is an effect on some common pathways (NF-KB, STATs) previously described to be affected in SS (10).
The genetic and epigenetic fine mapping of autoimmune risk factors was recently performed in 21 AID with the notable exception of SS (7). In line with our observations, it was observed that autoimmune risk variants were mostly non-coding $(90 \%)$ and map predominantly to $\mathrm{H} 3 \mathrm{~K} 27 \mathrm{Ac}$ positive immune-cell enhancers $(60 \%)$ and promoters $(8 \%)$. Next, a T cell signature was observed in nearly all of the AID tested except in lupus and primary billiary cirrhosis (two AID frequently associated with SS) that present a B cell signature, and type I diabetes with pancreatic islets. Finally, it was reported that autoimmune risk factors were enriched within binding sites for immune-related TFs, such as $\mathrm{Pu}-1$ and NF- $\mathrm{\kappa B}$. As a consequence, the physiopathology of AID needs to be updated according to the recent progress in epigenetics (54). 
Some limitations are inherent in this type of study. First, cells used in the ENCODE program are predominantly cell lines that are different from primary cells, such as the lymphoblastoid GM12878 B cell line, that results from EBV transformation of peripheral blood mononuclear cell using phytohemagglutinin as a mitogen. New results using primary cells, which are available from the Epigenome Roadmap program further supports similarities between lymphoblastoid GM12878 B cells and purified human $\mathrm{CD} 20^{+} \mathrm{B}$ cells as we observed for the FAM167A-BLK locus when using the RegulomeDB tool. Second, although the ENCODE program is an extensive resource; the program is limited to certain cell types and DNA binding elements that limit the interpretation. Third, many SNPs are in tight genetic linkage and, as a consequence, genetic risk variants may not be causal, but rather reveal the presence of a linked SNP that is functionally relevant to the pathogenesis. Such a situation may be suspected for different SNPs tested from our selection since the LD analysis has revealed new missense mutations as well as new gene risk factors that need to be tested, such as chemokines (CCL7 and CCL11), cytokines (IL2) and the miRNA4752. Two SNPs in CCL11 have been associated with germinal center-like structure formation in SS patients (47), and CCL11 (Eotaxin) circulating levels were reduced in SS patients (58).

While the function of the protein encoded by FAM167A is unknown, the tyrosine kinase BLK controls B cell development and is activated after $B$ cell receptor engagement. The FAM167A-BLK locus is associated with several AID, such as SS, lupus, rheumatoid arthritis, scleroderma, and vasculitis. Among them, two risk alleles (rs132771113 and rs9222483) are known to control BLK transcription during B cell development (53, 59). Moreover, by integrating epigenetic fine mapping, we further observed that all BLK-associated SS risk variants, including the two previously described, were all present within epigenetic marks in B cells. Altogether, this example illustrates the value of integrating epigenetic resources for investigating the complex mechanisms by which non-coding risk variants could modulate gene expression.

Last but not least, the B cell subset identified from our in silico study deserves several comments. First, B cell qualitative abnormalities have been reported in SS with important perturbations

\section{References}

1. Mavragani CP, Moutsopoulos HM. Sjogren's syndrome. Annu Rev Pathol (2014) 9:273-85. doi:10.1146/annurev-pathol-012513-104728

2. Voulgarelis M, Dafni UG, Isenberg DA, Moutsopoulos HM. Malignant lymphoma in primary Sjogren's syndrome: a multicenter, retrospective, clinical study by the European concerted action on Sjogren's syndrome. Arthritis Rheum (1999) 42:1765-72. doi:10.1002/1529-0131(199908)4

3. Baimpa E, Dahabreh IJ, Voulgarelis M, Moutsopoulos HM. Hematologic manifestations and predictors of lymphoma development in primary Sjogren syndrome: clinical and pathophysiologic aspects. Medicine (Baltimore) (2009) 88:284-93. doi:10.1097/MD.0b013e3181b76ab5

4. Tobon GJ, Renaudineau Y, Hillion S, Cornec D, Devauchelle-Pensec V, Youinou $\mathrm{P}$, et al. The FMS-like tyrosine kinase 3 ligand, a mediator of $\mathrm{B}$ cell survival, is also a marker of lymphoma in primary Sjogren's syndrome. Arthritis Rheum (2010) 62:3447-56. doi:10.1002/art.27611

5. Cornec D, Saraux A, Pers JO, Jousse-Joulin S, Marhadour T, RoguedasContios AM, et al. Diagnostic accuracy of blood B-cell subset profiling and in peripheral blood $\mathrm{B}$ cell profiling and $\mathrm{B}$ cell migration within exocrine glands $(5,60)$. Second, the association between the incidences of B cells in salivary gland epithelial cells has been addressed as well as the formation of ectopic germinal centers and transformation to B cell lymphoma (61). Third, non-HLA genetic associations in SS are predominantly related to $\mathrm{B}$ cell genes (BTK, CD40, EBF-1 ...) as we observed in our selection. Fourth, a recent study reported DNA methylation changes in $\mathrm{B}$ cells and such changes predominate within loci containing SS risk factors (16). Altogether, these observations provide rationale for targeting B cells in SS along with the observations that depleting B cells with Rituximab or targeting BAFF with Belimumab are both effective $(62,63)$.

In conclusion, we have tested, as a proof of concept, a novel approach that integrates both epigenetic information and results from genomic analysis to further enhance the value of the genetic risk factors highlighted in complex diseases, such as SS. Future work needs to be done in order to confirm experimentally the cellular specificity and the functional role of the characterized regulatory SNPs. Another consequence is that such approach could be used to select and/or propose future therapeutic drugs in SS as epigenetic mechanisms are reversible.

\section{Acknowledgments}

Authors are grateful to Simone Forest and Genevieve Michel for their secretarial assistance. This work is supported by the Ligue Contre le Cancer, the Region Bretagne, the Association Française du Gougerot Sjögren et des Syndrome Secs (AFGS), the Association Laurette Fugain (grant 1674), and the Association Dentaire Française (ADF). The research leading to these results has received support from the Innovative Medicines Initiative Joint Undertaking under grant agreement no. 115565, resources of which are composed of financial contribution from the European Union's Seventh Framework Programme (FP7/2007-2013) and EFPIA companies' in-kind contribution.

\section{Supplementary Material}

The Supplementary Material for this article can be found online at http://journal.frontiersin.org/article/10.3389/fimmu.2015.00437

autoimmunity markers in Sjogren's syndrome. Arthritis Res Ther (2014) 16:R15. doi:10.1186/ar4442

6. Cornec D, Saraux A, Jousse-Joulin S, Pers JO, Boisrame-Gastrin S, Renaudineau $\mathrm{Y}$, et al. The differential diagnosis of dry eyes, dry mouth, and parotidomegaly: a comprehensive review. Clin Rev Allergy Immunol (2014). doi:10.1007/s12016014-8431-1

7. Farh KK, Marson A, Zhu J, Kleinewietfeld M, Housley WJ, Beik S, et al. Genetic and epigenetic fine mapping of causal autoimmune disease variants. Nature (2015) 518:337-43. doi:10.1038/nature13835

8. Kundaje A, Meuleman W, Ernst J, Bilenky M, Yen A, Heravi-Moussavi A, et al. Integrative analysis of 111 reference human epigenomes. Nature (2015) 518:317-30. doi:10.1038/nature14248

9. Cruz-Tapias P, Rojas-Villarraga A, Maier-Moore S, Anaya JM. HLA and Sjogren's syndrome susceptibility. A meta-analysis of worldwide studies. Autoimmun Rev (2012) 11:281-7. doi:10.1016/j.autrev.2011.10.002

10. Burbelo PD, Ambatipudi K, Alevizos I. Genome-wide association studies in Sjögren's syndrome: what do the genes tell us about disease pathogenesis? Autoimmun Rev (2014) 13:756-61. doi:10.1016/j.autrev.2014.02.002 
11. Brooks WH, Le Dantec C, Pers JO, Youinou P, Renaudineau Y. Epigenetics and autoimmunity. J Autoimmun (2010) 34:J207-19. doi:10.1016/j.jaut.2009.12.006

12. Konsta OD, Thabet Y, Le Dantec C, Brooks WH, Tzioufas AG, Pers JO, et al. The contribution of epigenetics in Sjogren's syndrome. Front Genet (2014) 5:71. doi:10.3389/fgene.2014.00071

13. Konsta OD, Le Dantec C, Brooks WH, Renaudineau Y. Genetics and epigenetics of autoimmune diseases. eLS (2015):1-9. doi:10.1002/9780470015902.a0023593

14. Thabet Y, Le Dantec C, Ghedira I, Devauchelle V, Cornec D, Pers JO, et al. Epigenetic dysregulation in salivary glands from patients with primary Sjogren's syndrome may be ascribed to infiltrating B cells. J Autoimmun (2013) 41:175-81. doi:10.1016/j.jaut.2013.02.002

15. Altorok N, Coit P, Hughes T, Koelsch KA, Stone DU, Rasmussen A, et al. Genome-wide DNA methylation patterns in naive CD4+ T cells from patients with primary Sjogren's syndrome. Arthritis Rheumatol (2014) 66:731-9. doi:10. 1002/art.38264

16. Miceli-Richard C, Wang-Renault SF, Boudaoud S, Busato F, Lallemand C, Bethune $\mathrm{K}$, et al. Overlap between differentially methylated DNA regions in blood B lymphocytes and genetic at-risk loci in primary Sjogren's syndrome. Ann Rheum Dis (2015). doi:10.1136/annrheumdis-2014-206998

17. Le Dantec C, Varin MM, Brooks WH, Pers JO, Youinou P, Renaudineau Y. Epigenetics and Sjogren's syndrome. Cur Pharm Biotechnol (2012) 13:2046-53. doi:10.2174/138920112802273326

18. Le Dantec C, Vallet S, Brooks WH, Renaudineau Y. Human endogenous retrovirus group e and its involvement in diseases. Viruses (2015) 7:1238-57. doi:10.3390/v7031238

19. Nakken B, Jonsson R, Bolstad AI. Polymorphisms of the Ro52 gene associated with anti-Ro 52-kd autoantibodies in patients with primary Sjogren's syndrome. Arthritis Rheum (2001) 44:638-46. doi:10.1002/1529-0131(200103)44

20. Correa PA, Gomez LM, Cadena J, Anaya JM. Autoimmunity and tuberculosis. opposite association with TNF polymorphism. J Rheumatol (2005) 32:219-24.

21. Gomez LM, Anaya JM, Gonzalez CI, Pineda-Tamayo R, Otero W, Arango A, et al. PTPN22 C1858T polymorphism in Colombian patients with autoimmune diseases. Genes Immun (2005) 6:628-31. doi:10.1038/sj.gene.6364261

22. Miceli-Richard C, Comets E, Loiseau P, Puechal X, Hachulla E, Mariette X. Association of an IRF5 gene functional polymorphism with Sjogren's syndrome. Arthritis Rheum (2007) 56:3989-94. doi:10.1002/art.23142

23. Korman BD, Alba MI, Le JM, Alevizos I, Smith JA, Nikolov NP, et al. Variant form of STAT4 is associated with primary Sjogren's syndrome. Genes Immun (2008) 9:267-70. doi:10.1038/gene.2008.1

24. Nordmark G, Kristjansdottir G, Theander E, Eriksson P, Brun JG, Wang C, et al. Additive effects of the major risk alleles of IRF5 and STAT4 in primary Sjogren's syndrome. Genes Immun (2009) 10:68-76. doi:10.1038/gene.2008.94

25. Delgado-Vega AM, Castiblanco J, Gomez LM, Diaz-Gallo LM, Rojas-Villarraga A, Anaya JM. Bcl-2 antagonist killer 1 (BAK1) polymorphisms influence the risk of developing autoimmune rheumatic diseases in women. Ann Rheum Dis (2010) 69:462-5. doi:10.1136/ard.2008.100818

26. Gestermann N, Mekinian A, Comets E, Loiseau P, Puechal X, Hachulla E, et al. STAT4 is a confirmed genetic risk factor for Sjogren's syndrome and could be involved in type 1 interferon pathway signaling. Genes Immun (2010) 11:432-8. doi:10.1038/gene.2010.29

27. Iwamoto N, Kawakami A, Arima K, Nakamura H, Kawashiri SY, Tamai M, et al. Regulation of disease susceptibility and mononuclear cell infiltration into the labial salivary glands of Sjogren's syndrome by monocyte chemotactic protein-1. Rheumatology (Oxford). (2010) 49:1472-8. doi:10.1093/ rheumatology/keq079

28. Maiti AK, Kim-Howard X, Viswanathan P, Guillen L, Rojas-Villarraga A, Deshmukh $\mathrm{H}$, et al. Confirmation of an association between rs6822844 at the Il2-Il21 region and multiple autoimmune diseases: evidence of a general susceptibility locus. Arthritis Rheum (2010) 62:323-9. doi:10.1002/art.27222

29. Palomino-Morales RJ, Diaz-Gallo LM, Witte T, Anaya JM, Martin J. Influence of STAT4 polymorphism in primary Sjogren's syndrome. J Rheumatol (2010) 37:1016-9. doi:10.3899/jrheum.091007

30. Appel S, Le Hellard S, Bruland O, Brun JG, Omdal R, Kristjansdottir G, et al. Potential association of muscarinic receptor 3 gene variants with primary Sjogren's syndrome. Ann Rheum Dis (2011) 70:1327-9. doi:10.1136/ard.2010. 138966

31. Nordmark G, Kristjansdottir G, Theander E, Appel S, Eriksson P, Vasaitis L, et al. Association of EBF1, FAM167A(C8orf13)-BLK and TNFSF4 gene variants with primary Sjogren's syndrome. Genes Immun (2011) 12:100-9. doi:10.1038/ gene.2010.44

32. Bolstad AI, Le Hellard S, Kristjansdottir G, Vasaitis L, Kvarnstrom M, Sjowall $\mathrm{C}$, et al. Association between genetic variants in the tumour necrosis factor/lymphotoxin alpha/lymphotoxin beta locus and primary Sjogren's syndrome in Scandinavian samples. Ann Rheum Dis (2012) 71:981-8. doi:10.1136/ annrheumdis-2011-200446

33. Cay HF, Sezer I, Dogan S, Felek R, Aslan M. Polymorphism in the TNF-alpha gene promoter at position -1031 is associated with increased circulating levels of TNF-alpha, myeloperoxidase and nitrotyrosine in primary Sjogren's syndrome. Clin Exp Rheumatol (2012) 30:843-9.

34. Kong F, Li JX, Li P, Li YZ, Zhang FC, Zhang J. Association of TNFSF4 polymorphisms with susceptibility to primary Sjogren's syndrome and primary biliary cirrhosis in a Chinese Han population. Clin Exp Rheumatol (2013) 31:546-51.

35. Lessard CJ, Li H, Adrianto I, Ice JA, Rasmussen A, Grundahl KM, et al. Variants at multiple loci implicated in both innate and adaptive immune responses are associated with Sjogren's syndrome. Nat Genet (2013) 45:1284-92. doi:10.1038/ ng. 2792

36. Li Y, Zhang K, Chen $\mathrm{H}$, Sun F, Xu J, Wu Z, et al. A genome-wide association study in Han Chinese identifies a susceptibility locus for primary Sjogren's syndrome at 7q11.23. Nat Genet (2013) 45:1361-5. doi:10.1038/ng.2779

37. Nocturne G, Boudaoud S, Miceli-Richard C, Viengchareun S, Lazure T, Nititham J, et al. Germline and somatic genetic variations of TNFAIP3 in lymphoma complicating primary Sjogren's syndrome. Blood (2013) 122:4068-76. doi:10.1182/blood-2013-05-503383

38. Nordmark G, Wang C, Vasaitis L, Eriksson P, Theander E, Kvarnstrom M, et al. Association of genes in the NF-kappaB pathway with antibody-positive primary Sjogren's syndrome. Scand J Immunol (2013) 78:447-54. doi:10.1111/sji.12101

39. Rusakiewicz S, Nocturne G, Lazure T, Semeraro M, Flament C, Caillat-Zucman $\mathrm{S}$, et al. NCR3/NKp30 contributes to pathogenesis in primary Sjogren's syndrome. Sci Transl Med (2013) 5:195ra196. doi:10.1126/scitranslmed.3005727

40. Sun F, Li P, Chen H, Wu Z, Xu J, Shen M, et al. Association studies of TNFSF4, TNFAIP3 and FAM167A-BLK polymorphisms with primary Sjogren's syndrome in Han Chinese. J. Hum. Genet (2013) 58:475-9. doi:10.1038/jhg. 2013.26

41. Sun F, Xu J, Wu Z, Li P, Chen H, Su J, et al. Polymorphisms in the FAM167ABLK, but not BANK1, are associated with primary Sjogren's syndrome in a Han Chinese population. Clin Exp Rheumatol (2013) 31:704-10.

42. Zheng J, Yin J, Huang R, Petersen F, Yu X. Meta-analysis reveals an association of STAT4 polymorphisms with systemic autoimmune disorders and antidsDNA antibody. Hum Immunol (2013) 74:986-92. doi:10.1016/j.humimm. 2013.04.034

43. Du Y, Su Y, He J, Yang Y, Shi Y, Cui Y, et al. Impact of the leucocyte immunoglobulin-like receptor A3 (LILRA3) on susceptibility and subphenotypes of systemic lupus erythematosus and Sjogren's syndrome. Ann Rheum Dis (2014). doi:10.1136/annrheumdis-2013-204441

44. Nezos A, Papageorgiou A, Fragoulis G, Ioakeimidis D, Koutsilieris M, Tzioufas AG, et al. B-cell activating factor genetic variants in lymphomagenesis associated with primary Sjogren's syndrome. J Autoimmun (2014) 51:89-98. doi:10.1016/j.jaut.2013.04.005

45. Norheim KB, Le Hellard S, Nordmark G, Harboe E, Goransson L, Brun JG, et al. A possible genetic association with chronic fatigue in primary Sjogren's syndrome: a candidate gene study. Rheumatol Int (2014) 34:191-7. doi:10.1007/ s00296-013-2850-9

46. Paradowska-Gorycka A, Raszkiewicz B, Jurkowska M, Felis-Giemza A, Romanowska-Prochnicka K, Manczak M, et al. Association of single nucleotide polymorphisms in the IL27 gene with rheumatoid arthritis. Scand J Immunol (2014) 80:298-305. doi:10.1111/sji.12209

47. Reksten TR, Johnsen SJ, Jonsson MV, Omdal R, Brun JG, Theander E, et al. Genetic associations to germinal centre formation in primary Sjogren's syndrome. Ann Rheum Dis (2014) 73:1253-8. doi:10.1136/annrheumdis-2012202500

48. Song GG, Bae SC, Seo YH, Kim JH, Choi SJ, Ji JD, et al. Meta-analysis of functional MBL polymorphisms. Associations with rheumatoid arthritis and primary Sjogren's syndrome. Z Rheumatol (2014) 73:657-64. doi:10.1007/ s00393-014-1408-x

49. Zheng J, Huang R, Huang Q, Deng F, Chen Y, Yin J, et al. The GTF2I rs117026326 polymorphism is associated with anti-SSA-positive primary 
Sjogren's syndrome. Rheumatology (Oxford) (2015) 54:562-4. doi:10.1093/ rheumatology/keu466

50. Boyle AP, Hong EL, Hariharan M, Cheng Y, Schaub MA, Kasowski M, et al. Annotation of functional variation in personal genomes using RegulomeDB. Genome Res (2012) 22:1790-7. doi:10.1101/gr.137323.112

51. Ward LD, Kellis M. HaploReg: a resource for exploring chromatin states, conservation, and regulatory motif alterations within sets of genetically linked variants. Nucl Acids Res (2012) 40:D930-4. doi:10.1093/nar/gkr917

52. Ernst J, Kellis M. ChromHMM: automating chromatin-state discovery and characterization. Nat Methods (2012) 9:215-6. doi:10.1038/nmeth.1906

53. Guthridge JM, Lu R, Sun H, Sun C, Wiley GB, Dominguez N, et al. Two functional lupus-associated BLK promoter variants control cell-type- and developmental-stage-specific transcription. Am J Hum Genet (2014) 94:586-98. doi:10.1016/j.ajhg.2014.03.008

54. Le Dantec C, Brooks WH, Renaudineau Y. Epigenomic revolution in autoimmune diseases. World J Immunol (2015) 5:62-5. doi:10.5411/wji.v5.i2.00

55. Le Dantec C, Gazeau P, Mukherjee S, Brooks WH, Renaudineau Y. How the environment influences epigenetics, DNA methylation, and autoimmune diseases. Epigenetics and Dermatology. Elsevier (2015). p. 467-87.

56. Fraga MF, Ballestar E, Paz MF, Ropero S, Setien F, Ballestar ML, et al. Epigenetic differences arise during the lifetime of monozygotic twins. Proc Natl Acad Sci U S A. (2005) 102:10604-9. doi:10.1073/pnas.0500398102

57. Tsaprouni LG, Yang TP, Bell J, Dick KJ, Kanoni S, Nisbet J, et al. Cigarette smoking reduces DNA methylation levels at multiple genomic loci but the effect is partially reversible upon cessation. Epigenetics (2014) 9:1382-96. doi:10.4161/ 15592294.2014.969637

58. Szodoray P, Alex P, Brun JG, Centola M, Jonsson R. Circulating cytokines in primary Sjogren's syndrome determined by a multiplex cytokine array system. Scand J Immunol (2004) 59:592-9. doi:10.1111/j.0300-9475.2004.01432.x
59. Hom G, Graham RR, Modrek B, Taylor KE, Ortmann W, Garnier S, et al. Association of systemic lupus erythematosus with C8orf13-BLK and ITGAMITGAX. N Engl J Med (2008) 358:900-9. doi:10.1056/NEJMoa0707865

60. Alonso R, Buors C, Le Dantec C, Hillion S, Pers JO, Saraux A, et al. Aberrant expression of CD6 on B-cell subsets from patients with Sjogren's syndrome. J Autoimmun (2010) 35:336-41. doi:10.1016/j.jaut.2010.07.005

61. Christodoulou MI, Kapsogeorgou EK, Moutsopoulos HM. Characteristics of the minor salivary gland infiltrates in Sjogren's syndrome. J Autoimmun (2010) 34:400-7. doi:10.1016/j.jaut.2009.10.004

62. Devauchelle-Pensec V, Pennec Y, Morvan J, Pers JO, Daridon C, Jousse-Joulin S, et al. Improvement of Sjogren's syndrome after two infusions of rituximab (anti-CD20). Arthritis Rheum (2007) 57:310-7. doi:10.1002/art.22536

63. Pontarini E, Fabris M, Quartuccio L, Cappeletti M, Calcaterra F, Roberto A, et al. Treatment with belimumab restores B cell subsets and their expression of B cell activating factor receptor in patients with primary Sjogren's syndrome. Rheumatology (Oxford) (2015) 54:1429-34. doi:10.1093/rheumatology/kev005

Conflict of Interest Statement: The authors declare that the research was conducted in the absence of any commercial or financial relationships that could be construed as a potential conflict of interest.

Copyright $\odot 2015$ Konsta, Le Dantec, Charras, Brooks, Arleevskaya, Bordron and Renaudineau. This is an open-access article distributed under the terms of the Creative Commons Attribution License (CC BY). The use, distribution or reproduction in other forums is permitted, provided the original author(s) or licensor are credited and that the original publication in this journal is cited, in accordance with accepted academic practice. No use, distribution or reproduction is permitted which does not comply with these terms. 